University of Wollongong

Research Online

Faculty of Social Sciences - Papers (Archive) Faculty of Arts, Social Sciences \& Humanities

2019

Engaging with Bourdieu's theory of practice: an empirical tool for exploring school students' technology practice

Tiffani L. Apps

University of Wollongong, tiffani@uow.edu.au

Karley A. Beckman

University of Wollongong, karleymc@uow.edu.au

Sue Bennett

University of Wollongong, sbennett@uow.edu.au

Follow this and additional works at: https://ro.uow.edu.au/sspapers

Part of the Education Commons, and the Social and Behavioral Sciences Commons

Research Online is the open access institutional repository for the University of Wollongong. For further information contact the UOW Library: research-pubs@uow.edu.au 


\title{
Engaging with Bourdieu's theory of practice: an empirical tool for exploring school students' technology practice
}

\author{
Abstract \\ This article presents Bourdieu's theory of practice as a tool for exploring school students' technology \\ practice in empirical research. The authors provide educational technology researchers with an \\ accessible introduction to the theory of practice. They then detail the conceptual, methodological and \\ analytic application of the theory of practice in two educational technology studies. The application of the \\ theory in the two studies highlights the potential of the sociological framing for informing a robust critical \\ research agenda and understanding the circumstances that can contribute to digital inequalities. \\ Practically, knowledge gained through theoretically informed research is critical for researchers, \\ governments, schools and teachers in working to overcome digital inequalities.

\section{Disciplines} \\ Education | Social and Behavioral Sciences

\section{Publication Details} \\ Apps, T., Beckman, K. \& Bennett, S. (2019). Engaging with Bourdieu's theory of practice: an empirical tool \\ for exploring school students' technology practice. Technology, Pedagogy and Education, 28 (4), 413-423.
}




\title{
Engaging with Bourdieu's theory of practice: An empirical tool for exploring school students' technology practice
}

\begin{abstract}
This paper presents Bourdieu's theory of practice as a tool for exploring school students' technology practice in empirical research. We provide educational technology researchers with an accessible introduction to the theory of practice. We then detail the conceptual, methodological and analytic application of the theory of practice in two educational technology studies. The application of the theory in the two studies highlights the potential of the sociological framing for informing a robust critical research agenda and understanding the circumstances that contribute to digital inequalities. Practically, knowledge gained through theoretically informed research is critical for researchers, governments, schools and teachers in working to overcome digital inequalities.
\end{abstract}

Keywords: Bourdieu's theory of practice; school student; technology practice; digital inequality; research methods

\section{Introduction}

International research over the past 15 years shows consistent patterns of digital inequality in school students' digital skills and knowledge (OECD, 2010, 2015). This is despite increased access to cheaper and more accessible technologies, significant international investment in infrastructure and development of policy and curriculum aimed to support the development of digital skills and knowledge. The persistence of such patterns suggests that addressing digital inequalities is more complex than improved access, policy and curriculum. Educational technology research must explore the reasons behind patterns of inequality in digital skills and knowledge in order to better understand students' learning needs. We argue that such work would benefit from the application of a robust sociological lens to frame understanding of students' technology practice. This paper presents Bourdieu's theory of practice (1990) as one example of practice theory that has been applied in other areas of educational and social 
research to explore social disparities. We use the term 'technology practice' throughout this paper to acknowledge that students' experience, including skills and knowledge, with technology is more complex than what young people do with technology. The term practice recognises the act as embedded in the context as a meaning-making, structuring activity including the social and cultural relations, systems and structures, and significance the practice has in the individual's life (Nicolini, 2012). The aim of this paper is twofold. First, the value of the theory of practice in educational technology research will be discussed. Second, the theoretical constructs are introduced and examples of the conceptual, methodological and analytic application in two doctoral studies are presented (Apps, 2015; Beckman, 2015). It is intended that the concise and practical introduction to the theory of practice in educational technology may serve as a guide to educational technology researchers, particularly those with a developing understanding of Bourdieu’s sociology, to explore students' technology practice.

\section{Background}

Bourdieu's theory of practice (1990) is a set of thinking tools for analysing complex and subtle social structures and relationships that contribute to differences in an individual's practice (Bourdieu \& Wacquant, 1992). The application of the theory of practice to educational settings has made significant contributions to understanding the role that schools and education systems play in reinforcing social and cultural inequalities. For many students, the school and classroom operate on a different set of stakes, power relations, resources and struggles to other fields, such as their homes. This difference is greater for some students than others, as school often assumes dominant middle class culture, values and attitudes. Thus, students from other backgrounds tend to be disadvantaged at school, regardless of how diverse and rich their experience (Henry, Knight, Lingard, \& Taylor, 2006). The theory of practice offers a way of empirically 
understanding not just what schools do to students, but how they do it (Mills, 2008).

The emerging body of educational technology research that has applied the theory of practice in school settings highlights the potential of the sociological framing to provide a deep situated understanding about how and why digital inequalities occur (Beckman, Apps, Bennett, \& Lockyer, 2018). For example, findings from this research suggest that students' technology practice is influenced by their dispositions or inclinations towards technology, which influences how they engage with technology, seek technology-based experiences and perceive technology possibilities (Beckman, Bennett, \& Lockyer, 2014; Johnson, 2009; Kapitzke, 2000; North, Snyder, \& Bulfin, 2008; Robinson, 2011; Taylor, 2005). Further, students’ technology practice is shaped by the social aspects of their experiences via cultures of technology use, particularly through networks of supports and social exchanges (referred to as capital) (Selwyn, 2004). Access to such social and cultural capital is critical to build digital skills and frames our conceptualisation of future possibilities with technology. Students from middle class, privileged families tend to have larger stocks of the kind of formal technology-related capital valued in school than their peers from less privileged homes (Bulfin \& North, 2007; Cranmer, 2006; Hollingworth, Mansaray, Allen, \& Rose, 2011; North et al., 2008). Because of this, many educational experiences that aim to increase digital skills and competencies reproduce existing social and digital inequality. Moving beyond a binary view of digital inequality, a small body of research has focused on exploring the strategies that highly motivated and skilled students, from a range of family backgrounds, seek to expand their digital skills, knowledge and networks (capital) (Apps, 2015; Robinson, 2011, 2014). This research demonstrates the value of employing Bourdieu's theory of practice in educational technology research to reveal factors which work to enable and constrain technology practice. This is important for 
educational technology researchers in order to better inform initiatives to overcome digital inequality. Understanding individual and contextual factors that limit the impact of school curriculum designed to build digital skills and knowledge is the first step towards more transformative teaching and learning practices.

While Bourdieu’s work offers a conceptual, methodological and analytical lens to examine digital inequality, it is has been criticised for its density and inaccessibility (Jenkins, 2014). We propose challenges associated with the accessibility of the theoretical constructs and perceived relevance to educational technology research may be a barrier to uptake. We suggest that such criticisms may be a result, in part, of the inexplicit and partial description of the application of the theory in research methodologies.

This paper seeks to addresses such challenges by providing educational technology researchers with an accessible introduction to the theory of practice. To do this, we first provide an overview of Bourdieu's thinking tools. We then discuss the theory’s empirical application to educational technology research conceptually, methodologically and analytically, by presenting its application in two studies (Apps, 2015; Beckman, 2015). The operationalisation of the theory and application in the two studies highlights the potential of this sociological framing in educational technology research for understanding the circumstances that contribute to digital inequality. Finally, we invite researchers to employ Bourdieu’s theory to explore technology practice and share their research design with transparency, to support further development and critique of its application in educational technology research.

\section{The theory of practice - An overview of Bourdieu's thinking tools}

Bourdieu's theory of practice is a set of 'thinking tools' for analysing the 'life worlds' of individuals through empirical investigations (Bourdieu \& Wacquant, 1992). Bourdieu 
expressed this as an equation: [(habitus) (capital)] + field = practice] (Bourdieu, 1984, p. 101). Practice refers to an individual's actions and behaviour, which results from the relations between one’s dispositions (habitus) and one’s position in a field (capital), within the current state of play of that social arena (field) (Maton, 2012).

Habitus encompasses the dispositions that influence individuals to become who they are (Bourdieu, 1990). Habitus operates below the level of calculation and consciousness, underlying the conditioning and orienting practices by providing individuals with a sense of how to act and respond "without consciously obeying rules explicitly exposed as such” (Bourdieu, 1990, p. 76). Habitus is 'structured’ by one’s past and present circumstances, such as family upbringing and educational experiences. It is also generative, in that one's habitus helps to shape one's present and future practices. It is a 'structure' in that it is systematically ordered (Maton, 2012). Habitus disposes actors to do certain things, orienting actions and inclinations without strictly determining them (Mills, 2008). For Bourdieu, habitus is fundamentally connected to the field(s) within which it is developed (Bourdieu, 1984). Hence, practices are not simply the result of one's habitus but rather of relations between one's habitus and conditions within the field (Maton, 2012).

Fields, according to Bourdieu, are "networks of social relations, structured systems of social position within which struggles or manoeuvres take place over resources, stakes and access” (Everett, 2002, p. 60). The field functions like a game. All play the same game, though not necessarily consciously so or with the same advantage (Bourdieu, 1984). Society as a whole is a field structured according to relations of domination. Society also contains a range of fields, and should be seen as the dominant field from which other fields are never fully separated (Peillon, 1998). Habitus and field are relational structures, and it is the relation between these structures that provides the 
key for understanding practice. Each helps to shape the other and, significantly, both are also evolving, so relations between habitus and field are ongoing, dynamic and partial (Maton, 2012).

Bourdieu describes capital as the currency of the field (Grenfell, 2009). More specifically, capital acts as a social relation within a system of exchange. Bourdieu (1986) described three types of capital: economic, social and cultural capital. Economic capital includes one's material wealth. Cultural capital can be described as knowledge, skills, taste, aesthetic and cultural preferences, which may be: embodied; objectified via material resources or institutionalised qualifications. Social capital includes one’s contacts, affiliations and network(s) including the ability to derive benefit from these networks of connections (Bourdieu \& Richardson, 1986). All forms of capital are located within a system of competition and exchange whereby different capitals have different values in different fields. Put simply, this means that capital is not fixed, either within or across fields, or accumulated over time, and most capital can be exchanged into other forms.

The application of habitus, field and capital allows researchers to conceptualise and explore school student's technology use as a social practice, embedded in the contexts and purposes for which the technology is used. In this way, one's habitus is generative of the types of technology practices they may, or may not, be inclined to engage with and experience. As habitus is both a structuring and structured construct, a student's technological dispositions are shaped by the fields in which they operate and the technology practices they engage with. To illustrate the relational nature of these constructs, we present a hypothetical example. A student whose family encourages the use of technology for learning in the home may positively perceive similar uses at school. A student with these experiences may also be oriented toward or inclined to use 
technology for learning in various fields (disposition). Alternatively, a different student whose family uses technologies predominantly for leisure, may perceive technology practices in the school field as unfamiliar, difficult or irrelevant (Beckman et al., 2018). This is not to say the latter student has a deficit of skills and knowledge. As a deeper analysis of this student's home field, including the rules surrounding technology use, and orientation towards social or leisurely practices may reveal opportunities to develop less valued forms of cultural capital (e.g. time and freedom afforded to the student to operate in online gaming fields). Through this practice in the online field the student connects to other gamers to develop sophisticated gaming and online content creation skills. Extending this example, an understanding of the latter students' technology practice reveals opportunity to make connections between the fields of technology practice to develop formal school-based digital skills and knowledge for content creation.

'Technological capital' is a useful conceptual expansion of Bourdieu’s capital (1986), highlighting different forms that can be measured in terms of a person’s technology experience, while revealing the extent to which social class can play a role in technology use and proficiency (Selwyn, 2004). This conceptual work draws on the construct capital to explain the mediating role of economic, cultural and social resources in shaping individuals’ relationships to digital technologies. For example, the student above may be able to convert social and cultural capital, which they accumulated in the online gaming field into digital skills and knowledge valued in school field. This capital accumulation could support the student's further acquisition of digital skills and knowledge at school that is not typical of a student with narrow home experiences of technology. 


\section{The theory of 'research' practice - empirical tools}

The theory of practice is a theory of 'research' practice, intended to be exercised as an empirical tool (Grenfell, 2014). In this section, we discuss the empirical application of the theory of practice to educational technology research across three stages of empirical research: conceptually, methodologically and analytically (Grenfell, 2012; Hardy, 2012). To illustrate the application of the tools to educational technology research we draw on two recent doctoral studies as examples (Apps, 2015; Beckman, 2015). Studies One and Two investigated primary (Apps, 2015) and secondary students' (Beckman, 2015) technology practice through exploration of the students’ practice in context as detailed below in Table 1. 
Table 1. Overview of study examples

\begin{tabular}{|c|c|c|}
\hline & Study One (Apps, 2015) & Study Two (Beckman, 2015) \\
\hline Research Aims & $\begin{array}{l}\text { Investigated primary students' } \\
\text { school-based technology practice, } \\
\text { while paying attention to contextual } \\
\text { conditions, resources and } \\
\text { relationships that worked to shape } \\
\text { their technology practice, skills and } \\
\text { knowledge. }\end{array}$ & $\begin{array}{l}\text { Investigated secondary students' } \\
\text { technology practices as they } \\
\text { traversed school and everyday life } \\
\text { fields, to gain an understanding of } \\
\text { how students' perceptions, } \\
\text { dispositions, and circumstances } \\
\text { shaped technology practice. }\end{array}$ \\
\hline Study design & Embedded case study & Embedded case study \\
\hline Participants & $\begin{array}{l}28 \text { primary students ( } 12-13 \text { years } \\
\text { old, in their final year of primary } \\
\text { school) } \\
6 \text { embedded case students }\end{array}$ & $\begin{array}{l}64 \text { secondary students (13-16 years } \\
\text { old) from } 4 \text { class cases } \\
12 \text { embedded case students } \\
4 \text { class teachers }\end{array}$ \\
\hline Data collection & $\begin{array}{l}\text { Phase 1: Questionnaire and digital } \\
\text { recording of school-based digital } \\
\text { skills assessment (all students) } \\
\text { Phase 2: Semi-structured } \\
\text { interviews reflecting on digitally } \\
\text { captured school-based digital } \\
\text { literacy task (6 embedded case } \\
\text { students) } \\
\text { Phase 3: Family technology } \\
\text { interviews (conducted by all } \\
\text { students). }\end{array}$ & $\begin{array}{l}\text { Phase 1: Questionnaire (all } \\
\text { students), teacher interview } \\
\text { Phase 2: Technology diaries and } \\
\text { two semi-structured interviews } \\
\text { focused on general technology } \\
\text { practices and reflecting on } \\
\text { technology diary entries (12 } \\
\text { embedded case students) }\end{array}$ \\
\hline
\end{tabular}

\section{Conceptual application}

To employ the theory of practice first requires the researcher to apply the theoretical constructs within the field(s) of interest. Thus, the theoretical constructs become a set of thinking tools that pay attention to the complex interplay of social structures and relationships, which contribute to practice (Bourdieu \& Wacquant, 1992). This thinking then frames the construction of the research object, throughout the empirical process, by focusing on the systematic set of relationships associated with participants, institutions and the broader social space (Hardy, 2012). Specifically, habitus requires the research focus to be broader than the specific phenomena under investigation (Reay, 2004). To accomplish this, the researcher begins with the individual and then moves to the broader group under consideration (e.g. class, gender or race) to allow for an understanding of 
both the subjective (individuals as actively engaged in creating their social worlds) and objective (the predefined structure of those worlds) (Bourdieu \& Wacquant, 1992). To construct a research object, the researcher must identify the forms of valued capital that operate in it, and must have a sense of the logic of the field. In the studies described here, this meant identifying the valued technological capital within school fields as well as within everyday life contexts within which the students operated.

The conceptual expansion of technological capital (Selwyn, 2004) is particularly useful in focusing thinking about the social spaces (fields) in which students’ technology practices occur, including how structures within differing home fields work to shape technology possibilities. To glean a sense of the logic of such fields, the researcher might consider which technological capitals are valued, who holds family positions of power, the influence on family practices and how the accumulations of capital enable or constrain technology use. While field theory assists the researcher in thinking about the objective structures that shape practice, habitus focuses on the generative, yet structured, role of actors. Although habitus cannot be directly observed in empirical research, it can be ‘apprehended interpretively’ (Reay, 2004, p. 439). Thus, these studies focused on students' technology practices (including likes, time spent, purpose, motivation and confidence) and preferences toward certain practices in an attempt to understand students’ habitus. Useful questions to frame conceptual thinking around young people's technology habitus could include: What dispositions do students have toward digital technologies? Specifically, do students have preferences, orientations or inclinations towards certain practices? How do such expressions shape technology practices? How have such dispositions been manifested through systematic relationships and available capital within the family and broader social class group? Are dispositions an individual expression of agency or desire? Significantly, constructing a 
research object is an iterative process, thus the initial research object should be fluid (Bourdieu \& Wacquant, 1992).

Both study examples applied the theoretical constructs at a conceptual level, in the construction of the initial research object. Study One examined primary students' school-based technology practice, skills and knowledge, in context of their home technology practices, resources and relationships to gain an understanding of how students developed school-based digital literacy (Apps, 2015). Study Two explored secondary students' technology practices at school and outside of school, with a particular focus on understanding how and why students used and perceived technologies in various ways (Beckman, 2015). Table 2 details the conceptual application of the theory of practice in both examples, including habitus and field and drawing on Selwyn’s (2004) conceptualisation of technological capital (text directly quoted from Selwyn are indicated in italics in Table 2). Both studies focused on the interrelated nature of habitus, field and capital to uncover objective conditions, resources and dispositions that shape technology practice and possibilities. Such a focus allowed for a consideration of the complexity of students' technology practices and associated digital literacies, including the interplay of factors and relationships within home, school and the broader social field of power. 
Table 2. Conceptual application of the theory of practice in study examples

\begin{tabular}{|c|c|c|}
\hline Construct & Study One (Apps, 2015) & Study Two (Beckman, 2015) \\
\hline Habitus & $\begin{array}{l}\text { Personal dispositions (preferences } \\
\text { and orientation toward the use of } \\
\text { technology at home and school) } \\
\text { Regular technology practices in } \\
\text { the home }\end{array}$ & $\begin{array}{l}\text { Circumstances or background, including } \\
\text { family structure and parents' and siblings' } \\
\text { occupations } \\
\text { Personal disposition toward technology } \\
\text { (orientation or inclination toward certain } \\
\text { technology practices) } \\
\text { Past and present experiences with } \\
\text { technology } \\
\text { Shared beliefs and accepted practices with } \\
\text { technologies } \\
\text { Personal beliefs and perceptions about the } \\
\text { value of technologies }\end{array}$ \\
\hline Field & $\begin{array}{l}\text { Available technology resources } \\
\text { Access to technology resources } \\
\text { Culture of technology use } \\
\text { Rules and restrictions surrounding } \\
\text { family and children's technology } \\
\text { use } \\
\text { Position(s) of children and family } \\
\text { members in regard to technology } \\
\text { within field within home }\end{array}$ & $\begin{array}{l}\text { Technology resources available and } \\
\text { accessible } \\
\text { Location and distribution of technological } \\
\text { resources } \\
\text { Culture of technology use (including } \\
\text { rules, others' perceptions and practices) } \\
\text { Position in the field in relation to } \\
\text { technological capital } \\
\text { Being attuned to the "rules of the game” } \\
\text { of technology practices }\end{array}$ \\
\hline Economic & \multicolumn{2}{|c|}{$\begin{array}{l}\text { Material resourcing of students' home and school environments including } \\
\text { quality, quantity of equipment and capacity for maintenance and upgrade of } \\
\text { equipment. }\end{array}$} \\
\hline Social & \multirow{2}{*}{\multicolumn{2}{|c|}{$\begin{array}{l}\text { Networks of 'technological contacts' and support including } \\
\text { family, friends, neighbours, tutors and other 'significant others'; membership } \\
\text { of groups/organisations, online help facilities and commercial help lines } \\
\text { Embodied - Self interest in investing time into self-improvement of ICT skills } \\
\text { Active participation in ICT education both formal (within school) and informal } \\
\text { (outside of school) } \\
\text { Objectified - Socialisation into technology use and 'techno-culture' via techno- } \\
\text { cultural goods (e.g. exposure to ICT via magazines, books and other media), } \\
\text { family, peers and other agents of socialisation } \\
\text { Institutionalized - Formal (school) ICT learning }\end{array}$}} \\
\hline Cultural & & \\
\hline
\end{tabular}

\section{Methodological application}

Bourdieu's constructs provide a tool capable of capturing a dynamic representation of human activity that can be embedded in the design of the study and data collection strategy (Grenfell, 2012). Once the researcher constructs the initial research object, consideration can be given to the type of data required to apprehend details of 
participants' habitus, available capital, embodied and objective field conditions. In both study examples the guiding conceptual framework informed the design of the data collection strategy and tools.

Tables 3 and 4 provide an overview of the data collection tools developed for each study. Each table details how the guiding conceptual framework informed the design and focus of each data collection tool and is followed by a more detailed discussion of this process. As discussed earlier, the construction of the research object is an iterative process, thus the data collection tools were designed to be open-ended and exploratory in nature. 
Table 3. Study One (Apps, 2015): Overview of the alignment of data tools and theoretical constructs

\begin{tabular}{lll}
\hline Data tool & Data focus & Theoretical construct(s) \\
\hline Background & Parental occupation & Economic capital \\
& $\begin{array}{l}\text { Available technology resources } \\
\text { Student practices and } \\
\text { preferences: likes, dislikes, } \\
\text { interests, weekly practices, self- } \\
\text { efficacy }\end{array}$ & $\begin{array}{l}\text { Field conditions } \\
\text { Habitus }\end{array}$ \\
& $\begin{array}{l}\text { Student timetable of technology } \\
\text { use over a one-week period }\end{array}$ & $\begin{array}{l}\text { Habitus, embodied cultural } \\
\text { capital }\end{array}$ \\
& $\begin{array}{l}\text { Location of technology resources } \\
\text { Family members' weekly }\end{array}$ & $\begin{array}{l}\text { Field conditions, objectified } \\
\text { cultural capital and available } \\
\text { social capital }\end{array}$ \\
& $\begin{array}{l}\text { practices } \\
\text { Family timetable of technology }\end{array}$ & \\
use over a one-week period & \\
$\begin{array}{l}\text { School-based } \\
\text { digital } \\
\text { literacy task }\end{array}$ & $\begin{array}{l}\text { Digitally captured school-based } \\
\text { digital literacy assessment } \\
\text { (functional skills \& knowledge }\end{array}$ & $\begin{array}{l}\text { Cultural capital } \\
\text { (Institutionalised) }\end{array}$ \\
aligned with school curriculum) & \\
$\begin{array}{l}\text { Reflective } \\
\text { student } \\
\text { interviews }\end{array}$ & $\begin{array}{l}\text { Explore and explain digitally } \\
\text { captured school-based digital } \\
\text { literacy task performance in } \\
\text { relation to family practices }\end{array}$ & $\begin{array}{l}\text { Habitus, objectified cultural } \\
\text { capital, social capital and home } \\
\text { field conditions }\end{array}$ \\
$\begin{array}{l}\text { Student- } \\
\text { conducted } \\
\text { family } \\
\text { technology } \\
\text { interviews }\end{array}$ & $\begin{array}{l}\text { Family technology practices and } \\
\text { values }\end{array}$ & $\begin{array}{l}\text { Field conditions, objectified } \\
\text { cultural capital and available } \\
\text { social capital }\end{array}$ \\
\hline
\end{tabular}

In Study One (Apps, 2015), data was collected across three phases. Each was designed to capture a subjective representation of students' school-based digital literacy in context of their usual technology practice and relationships. During Phase 1 data was collected from one class of students in their final year of primary school and included a questionnaire and recorded digital literacy task. These measured students’ digital literacy performance in terms of functional skills and knowledge as defined by the school curriculum. The task was a regular component of the students' school work. The purpose of the first phase was to explore students' home technology practices and capture a representation of their school-based digital literacy. The questionnaire was 
open-ended and collected data about students’ family demographics and home technology practices and preferences. The school-based digital literacy task was digitally captured as a stimulus for student reflection interviews. Phase 2 of the study, involved six case students, purposefully selected from the broader sample of students to represent a range of digital literacy (capital), as measured in the Phase 1 task, and student background data captured in the questionnaire (habitus, field and capital). The case students participated in semi-structured reflection interviews using their digitally captured digital literacy task as stimulus. The purpose of this phase was to provide students with the opportunity to explore and explain their school-based digital literacy in context of their broader technology practices. We asked students to reflect on their key processes in the task and explain: what they were doing; where and how they had learned about the practice in focus; and where else they applied such skills and knowledge. Phase 3 of the study involved the class of students. Students conducted interviews with their family members about technology practices and preferences (habitus), with the purpose of providing further data about their home technology experiences to understand the negotiations students made across home and school fields when engaging with technologies. 
Table 4. Study Two (Beckman, 2015): Overview of the alignment of data tools and theoretical constructs

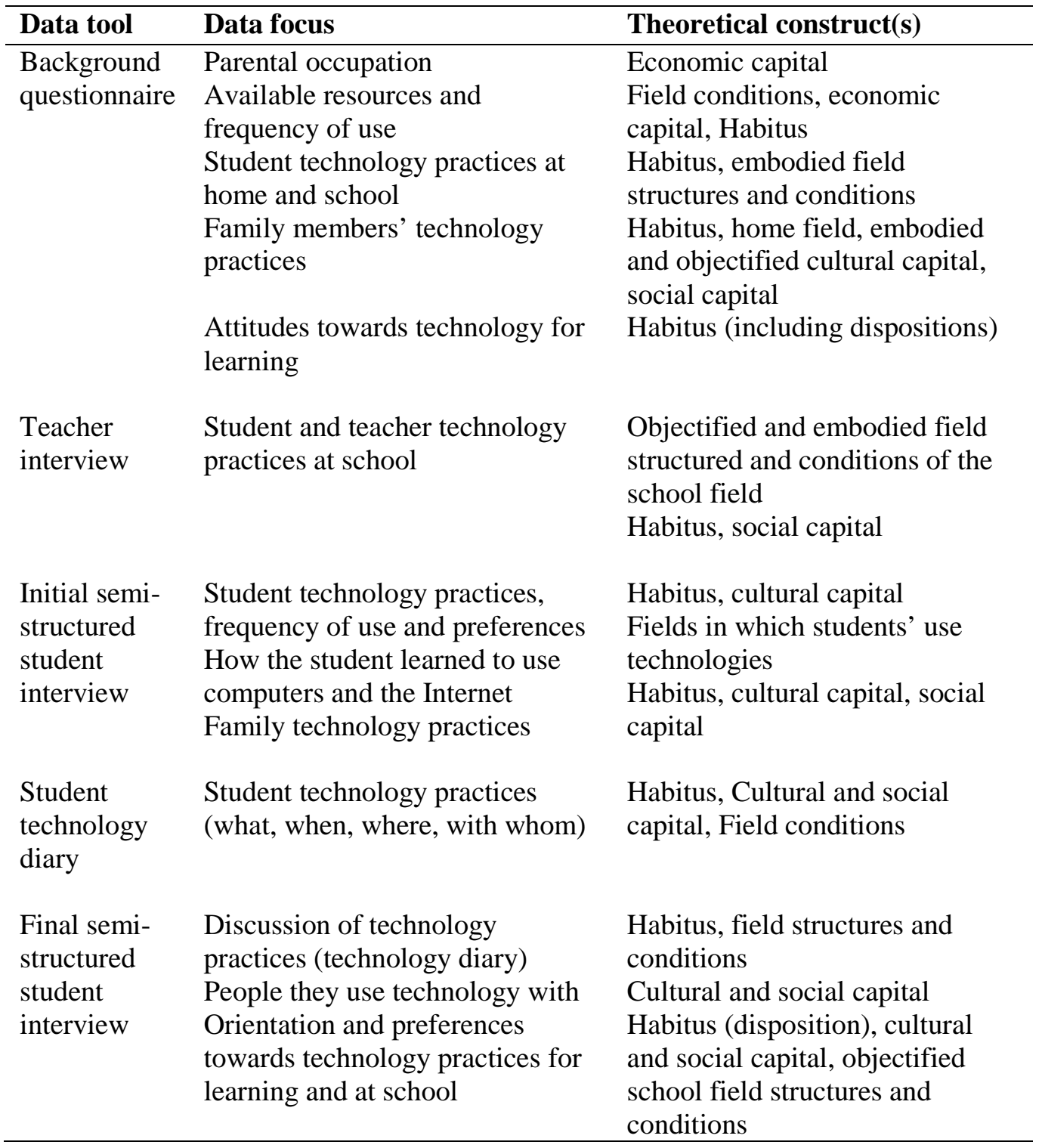

Study Two (Beckman, 2015) examined secondary students’ technology practices across two phases. Phase 1 of the study collected data from four participating classes, including a student questionnaire and teacher interview. The purpose of the first phase of the study was to explore the range of students' practices and begin to characterise their fields of technology practice, particularly school and home fields of technology use. The questionnaire items focused on students' backgrounds, including information about their family members and their technology practices, their access to and use of 
technologies at home and school, and their perspectives about themselves as technology users and the use of technology for learning. The teacher interviews provided rich detail about technology practices in the school field, including how they integrated technology into learning and how the teacher valued technology. Phase 2 of the study involved 12 students, purposefully selected from the broader group to represent a range of student backgrounds (habitus and capital) and technology practices. Phase 2 of the study comprised one-on-one interviews with each student to explore data from the questionnaire in more depth. Following this, students used a diary to record all their technology practices over a two-week period. Finally, the practices recorded in the diary were used as a stimulus for a final one-on-one semi-structured interview. The purpose of this phase of the study was to provide rich detail of students' technology practice, including details of their home and school contexts and disposition.

Overall, the methods used in the two studies allowed the researchers to capture a subjective and objective representation of students' technology practice and highlight the ways that both contextual factors and individual agency worked to constrain, enable or transform technology practice or school-based digital literacy within, between and across fields.

\section{Methodological considerations}

While the methodological approach of the two studies outlined captured a detailed understanding of student technology practice according to field, the scope of these studies does not represent a complete depiction of student technology practice, nor a full application of Bourdieu's theoretical constructs. The nature of the researcher's involvement in the research process inevitability limits the researcher's sociological 
gaze in some way (Bourdieu \& Wacquant, 1992), and thus determines the construction of the research object and aspects of the research design.

The research object defined by the researchers in both case study examples, focus only on a segment of technology practice. For example, Study One focused specifically on students' home and school fields to understand their school-based digital literacy. In defining the research object, additional fields were considered, yet given the young age of participants and the limited fields in which they interact a focus on home and school was taken. Further, the focus of the study was detailing a deeper understanding of the ways that participants' home technology experiences shaped their school-based digital literacy, thus data collection tools were focused on home and school fields. Similarly, Study Two, explored students’ technology practices, with a particular focus on providing understanding of students’ practice that may inform technology practice in formal education settings. The study was concerned only with digital technologies (e.g. computing hardware/devices, games consoles and hand-held games machines, computer software and online services), and thus excluded other forms of technology. In addition, the study acknowledged the influence of other field participants (such as teachers, peers and family) on students' technology practices, evidenced by the collection of data on teachers' technology practices. For example, while the interview methods only captured a segment of teachers' use and perceptions of technology for learning, the focus of this approach was to provide a more holistic understanding of how teachers' practices may shape students' technology practices.

The data collection tools (see Tables 3 and 4), informed by the theory of practice to capture contextual factors shaping technology practice, were not a complete representation of each theoretical construct. For example, in Study One habitus informed the design of data collection tools in terms of disposition or inclination 
towards the use of digital technologies, yet this is only one aspect of how Bourdieu defines habitus. Similarly, home and school fields were explored through semistructured interviews in both study examples, it was not the intention of the researchers to cover all structuring field conditions, instead interview protocols provided prompts, which allowed varying details to be offered by participants

\section{Analytic application}

The analytical application of the theory of practice provides a lens through which to understand the physical, social and cultural aspects of human activity to highlight the underlying logic of practice (Beckman et al., 2018; Lareau, 1997; Reay, 1998). In both study examples analysis begun at the individual construct level. This was followed by the construction of student profiles that integrated data from each construct, and allowed for analysis of the dynamic interrelationships of students' home and school fields that shaped practice. Profiles were then compared for common characteristics and differences. This stage of analysis is focused on developing categories that differentiate between students and groups of students (Hardy, 2012). For example, a shared inclination towards a certain technology practice or exposure to a wide variety of technology practices at home. Following this, analyses focused on positioning students and groups of students in relation to the broader social field, which in both studies was schooling and education. This iterative process allowed students' technology practices to be reconsidered at the individual level after consideration of the role of the broader social positioning on practice (Hardy, 2012; Reay, 2004).

To accomplish this iterative analysis Study One compiled student profiles, which were compared for common characteristics. Two key categories emerged from this analysis revealing different configurations of capital, dispositions and home field conditions. Common characteristics in the first category included students' school- 
based digital literacy performance and parental occupation group. The majority of students from working class families were outscored by their peers from middle class families. Commonly, these students experienced technology practice for leisure and access to technologically unskilled networks of support (social capital) in the family home. While their middle-class peers experienced a broader set of technology practices for work and leisure with access to skilled networks of support within the family home. The second category was constituted of several profiles, which did not neatly fit this parental occupation pattern typical of large scale patterns of digital inequality (OECD, 2015). This analysis illustrated the differences that existed between students' experiences and orientation to technologies (and those of their families) and, importantly, the strategies they embodied that worked to constrain, enable or transform school-based digital literacy.

Study Two focused on an analysis of the fields of students' technology practices. To accomplish this, analysis of the teachers' and students' (including students accounts of their peers) objectified field conditions, positions of power, rules and cultures of technology practice, provided a grounding through which to profile and understand individual students' technology practice. Following this students’ profiles were compared, focusing on differences and similarities in students' habitus and capital. Profiles were then analysed in context of the broader school field with a focus on the relationships between physical, individual and social factors that shaped how and why students use technology. The findings of this study demonstrate that students' technology practice was varied. Structured by their habitus, students were inclined to use technologies with which they had some familiarity or to which they had some exposure, based on their experiences at home and school and the likelihood of achieving the desired outcome. This exposure to certain practices and experiences with 
technologies shaped students' disposition towards certain uses of technology. Furthermore, the findings demonstrated that those students with networks of technological contacts and support, and a culture of technology use that was aligned with the school field were more likely to embrace technology practices for learning. Overall, analysis of these findings illustrates that students' technology practice are social and shaped by the participants, systems and structures within the field.

The central goal of Bourdieu's theory of practice is to uncover structures and mechanisms that work to ensure either reproduction or transformation (Bourdieu \& Richardson, 1986). The structures and systems of the school field are important considerations, not only to understand technology practices, but also to understand variations in students' technology practices and potential effects on student learning. The analysis presented in the two study examples demonstrated how the habitus and capital accumulation of some students were aligned with, and thus legitimised by the school field. While other students' habitus and capital had less or no currency in the school field. Study One illuminated the ways that such matches of habitus and capital between home and school were not strictly associated with family background. Importantly, such an approach offers educational technology researchers with the potential to look beyond a binary view to consider the factors behind patterns of inequality in digital skills and knowledge. While revealing the ways that students' technology practice is both enabled and constrained by individual and contextual factors both inside and outside of school. Understanding of the enabling and constraining factors may allow researchers and educators to design more transformative technology based learning experiences "to redefine the game and the moves which permit one to win in it” (Bourdieu, 1988, p. 172). 


\section{Opportunities for action}

The theory of practice provides a sociological lens for thinking about digital inequalities, as well as a set of practical research tools for exploring technology practices through empirical investigations. As the constructs have been criticised for being inaccessible, the central aim of this paper was to provide educational technology researchers with an accessible introduction to the theory as a set of empirical tools. The two studies presented in this paper provide examples of a practical approach to the application of the theory of practice in educational technology research. Operationalised as research tools, the theoretical constructs offer the potential to frame a more robust critical research agenda to uncover details of structure and agency in shaping technology practices that challenge educators and policy makers to bring about change. We invite educational technology researchers to engage with Bourdieu's theory of practice to explore children and young people's diverse technology practices. Importantly, we urge that sharing approaches to research designs, methodologies and analyses framed by theory is crucial in enabling further development and critique.

Practically, knowledge gained through theoretically informed research is critical for researchers, governments, schools and teachers. This understanding should form the basis of sound educational change that caters for all students through meaningful-situated connections designed to build capitals and increase possibilities, rather than reinforce existing inequalities. 


\section{References}

Apps, T. (2015). ICT literacy and the digital divide: Understanding primary students' ICT practices and possibilities (Doctor of Philosophy thesis). University of Wollongong.

Beckman, K. (2015). Secondary school students' technology practices in their everyday lives and at school (Doctor of Philosophy thesis). University of Wollongong.

Beckman, K., Apps, T., Bennett, S., \& Lockyer, L. (2018). Conceptualising technology practice in education using Bourdieu’s sociology. Learning, Media and Technology, 43(2), 197-210. https://doi.org/10.1080/17439884.2018.1462205

Beckman, K., Bennett, S., \& Lockyer, L. (2014). Understanding students' use and value of technology for learning. Learning, Media and Technology, 39(3), 346-367. https://doi.org/10.1080/17439884.2013.878353

Bourdieu, P. (1984). Distinction: A Social Critique of the Judgement of Taste. Harvard University Press.

Bourdieu, P. (1988). Homo Academicus. California: Stanford University Press.

Bourdieu, P. (1990). The Logic of Practice. Stanford University Press.

Bourdieu, P., \& Richardson, J. (1986). The forms of capital. In Handbook of theory and research for the sociology of education (pp. 241-256). Connecticut: Greenwood Press.

Bourdieu, P., \& Wacquant, L. J. D. (1992). An Invitation to Reflexive Sociology. Chicago: University of Chicago Press.

Bulfin, S., \& North, S. (2007). Negotiating Digital Literacy Practices Across School and Home: Case Studies of Young People in Australia. Language and Education, 21(3), 247-263. https://doi.org/10.2167/le750.0 
Cranmer, S. (2006). Children and young people’s uses of the Internet for homework. Learning, Media and Technology, 31(3), 301-315. https://doi.org/10.1080/17439880600893358

Everett, J. (2002). Organizational Research and the Praxeology of Pierre Bourdieu. Organizational Research Methods, 5(1), 56-80. https://doi.org/10.1177/1094428102051005

Grenfell, M. (2009). Applying Bourdieu’s field theory: the case of social capital and education. Education, Knowledge and Economy, 3(1), 17-34. https://doi.org/10.1080/17496890902786812

Grenfell, M. (2012). Methodology. In M. Grenfell (Ed.), Pierre Bourdieu: Key concepts (2nd ed.). Durham: Acumen Publishing Limited.

Grenfell, M. (2014). Pierre Bourdieu: Key Concepts. Routledge. Hardy, C. (2012). Social space. In M. Grenfell (Ed.), Pierre Bourdieu: Key concepts (2nd Edition, pp. 229-249). Durham: Acumen Publishing Limited.

Henry, M., Knight, J., Lingard, R., \& Taylor, S. (2006). Understanding Schooling: An Introductory Sociology of Australian Education. Routledge.

Hollingworth, S., Mansaray, A., Allen, K., \& Rose, A. (2011). Parents’ perspectives on technology and children's learning in the home: social class and the role of the habitus: Parents, social class and the role of the habitus. Journal of Computer Assisted Learning, 27(4), 347-360. https://doi.org/10.1111/j.13652729.2011.00431.x

Jenkins, R. (2014). Pierre Bourdieu. Routledge.

Johnson, N. F. (2009). Cyber-Relations in the Field of Home Computer Use for Leisure: Bourdieu and Teenage Technological Experts. E-Learning and Digital Media, 6(2), 187-197. https://doi.org/10.2304/elea.2009.6.2.187 
Kapitzke, C. (2000). Information Technology as Cultural Capital: Shifting the Boundaries of Power. Education and Information Technologies; New York, 5(1), 49-62. http://dx.doi.org/10.1023/A:1009640518635

Lareau, A. (1997). Social-Class differences in family-school relationships: The importance of cultural capital. In A. Halsey, H. Lauder, P. Brown, \& A. Wells (Eds.), Education: Culture, economy and society (pp. 703-717). Oxford: Oxford University Press.

Maton, K. (2012). Habitus. In M. Grenfell (Ed.), Pierre Bourdieu: Key concepts (2nd edition, pp. 48-64). Durham: Acumen.

Mills, C. (2008). Reproduction and transformation of inequalities in schooling: the transformative potential of the theoretical constructs of Bourdieu. British Journal of Sociology of Education, 29(1), 79-89. https://doi.org/10.1080/01425690701737481

North, S., Snyder, I., \& Bulfin, S. (2008). Digital tastes: Social class and young people’s technology use. Information, Communication \& Society, 11(7), 895911. https://doi.org/10.1080/13691180802109006

Nicolini, D. (2012). Practice Theory, Work, and Organization: An Introduction. Oxford University Press.

OECD. (2010). Are the New Millennium Learners Making the Grade? OECD Publishing. https://doi.org/10.1787/9789264076044-en

OECD. (2015). Students, Computers and Learning. OECD Publishing. https://doi.org/10.1787/9789264239555-en

Peillon, M. (1998). Bourdieu's Field and the Sociology of Welfare. Journal of Social Policy, 27, 213-229. 
Reay, D. (1998). Rethinking social class: qualitative perspectives on class and gender. Sociology, 32(2), 259-275.

Reay, D. (2004). 'It's all becoming a habitus': beyond the habitual use of habitus in educational research. British Journal of Sociology of Education, 25(4), 431-444. https://doi.org/10.1080/0142569042000236934

Robinson, L. (2011). Information-channel preferences and information-opportunity structures. Information, Communication \& Society, 14(4), 472-494. https://doi.org/10.1080/1369118X.2011.562224

Robinson, L. (2014). Endowed, Entrepreneurial, and Empowered-Strivers: Doing a lot with a lot, doing a lot with a little. Information, Communication \& Society, 17(5), 521-536. https://doi.org/10.1080/1369118X.2013.770049

Selwyn, N. (2004). Reconsidering Political and Popular Understandings of the Digital Divide. New Media \& Society, 6(3), 341-362. https://doi.org/10.1177/1461444804042519

Taylor, A. (2005). Finding the future that fits. Gender and Education, 17(2), 165-187. https://doi.org/10.1080/0954025042000301447 